\title{
Elastoplastic analysis of cracked Aluminum plates with a hybrid repair technique using the bonded composite patch and drilling hole in opening mode I
}

\author{
W. N. Bouzitouna \\ Smart Structures Laboratory, Univ Ctr of Ain Témouchent, Po Box 284,46000, Algeria \\ bibanesrine@outlook.fr
}

W. Oudad

Mechanical Engineering Department, Univ Ctr of Ain Témouchent, Po Box 284,46000, Algeria

oudadw@gmail.com, bttps:/ /orcid.org/0000-0002-3283-1322

\author{
M. Belhamiani, D. E. Belhadri \\ Smart Structures Laboratory, Univ Ctr of Ain Témouchent, Po Box 284,46000, Algeria \\ mbelhamiani@gmail.com, bttps://orcid.org/0000-0001-8951-032X \\ djamelins@hotmail.fr
}

L. Zouambi

Mechanical Physical Materials Laboratory, Mechanical Engineering Department, (LMPM) University Center of Relizane, 48000, Algeria

rouambileila1071@gmail.com

\begin{abstract}
The objective of this study is to analyze the performance of composite bonding repair, hole drilling and the combination of the two techniques (hybrid repairs) by tensile tests and to show the interest of a hybrid repair versus other processes. These repair techniques can apply in different branches of engineering: mechanical, aerospace, civil, naval, etc. The finite element method with the ABAQUS code was used to model the mechanical behavior of the different repair techniques. The Notch Stress Intensity Factor (NSIF) is adopted to model the behavior of the cracked notch based on the volumetric method. The size of the plastic zone, the intensity of the normal $\sigma_{y y}$ stress, the peel stress and CTOD are combined to model the proposed techniques repair. Although the bonded composite is very strong, the application of a drilling hole results in additional energy absorption and reduces the level of the maximum normal stress by about $50 \%$ compared to a simple patch only. The use of a hybrid repair has a high resistance compared to other proposed methods, improves the mechanical strength and increases the life of the cracked structure compared to a single composite joint and a repair by drilling hole only.
\end{abstract}

KEYwORDS. Hybrid; Bonded; Composite; NSIF; Plastic zone; Drilled.

\section{OPEN ACCESS}

Citation: Bouzitouna, W. N., Oudad, W., Belhamiani, M., Belhadri, D. E., Zouambi, L., Elastoplastic analysis of cracked Aluminum plates with a hybrid repair technique using the bonded composite patch and drilling hole in opening mode I, Frattura ed Integrità Strutturale, 52 (2020) 256-268.

Received: 17.11.2019

Accepted: 13.02 .2020

Published: 01.04.2020

Copyright: (C) 2020 This is an open access article under the terms of the CC-BY 4.0, which permits unrestricted use, distribution, and reproduction in any medium, provided the original author and source are credited. 


\section{INTRODUCTION}

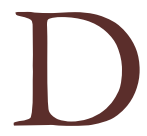

amage to metal aircraft structures is often caused by corrosion, erosion, normal stress, and accidents and mishaps, which made the component susceptible to cracking in service. The replacement of the cracked component can be very costly, thus it's important that metal structural repairs be made according to the best available techniques to expand its service life and investigate the satisfactory performance of an aircraft in a rapid way reducing the immobilization time of the device structure.

Numerous and varied crack repair techniques have been proposed for arresting or retarding crack propagation in structural components such as: i) the use of bonded composite patch repair, A Baker and al [1] explain the concept of using bonded composite materials as a mean to maintain aging metallic aircraft. The reinforcements of composite patch repairs reduce stresses in the cracked region and keeps the crack from opening and therefore from growing; ii) The infiltration method, which is based on reinforcing the cracked body by depositing closure material like epoxy resin along the crack path. [2] stated that crack growth retardation is promoted by through the infiltration of closure materials into a crack, and the closure material properties play a dominant role in promoting the crack closure and the retardation. iii) drilling a hole at the crack tip is one of the easiest and most accessible crack arresting procedures. Cracking resumes very shortly after drilling because of the high stress concentration associated with hole and this is why it remains temporary and relatively ineffective method [3, 4]; iv) a much superior approach is to stop drilling and then expand the stop hole, usually with a special sleeve to develop favorable compressive stresses that reduce or prevent crack opening, while this approach is often highly effective in stopping crack growth [4-6]. [5] studied the influence between the holes of different diameters and also between the expanded holes and non-expanded holes on arresting the crack propagation, finding that the number of cycles to initiate a new crack is three times longer than non-expanded holes; v) repair of corrosion types such as pitting or exfoliation in aluminum alloy structures generally involves the removal of visible damage by grinding followed by an extra confidence cut to ensure that all the corrosion is removed. The region is then treated, primed and painted. In the case of severe corrosion, panel thickness may be reduced below the allowable thickness and must be reinforced to make it airworthy [7-9]; vi) the overload repair is applied to the metallic structure in order to create a plastic zone over the crack-tip, this zone generates a residual compressive stress that leads to a decrease in the velocity of the crack growth, [10], that is explain by the closure of the crack caused by the plastic zone generated [11-14]; vii) another method based on the application of residual compressive stresses to reduce the crack growth rate is to press a steel ball in the crack-tip. $[15,16]$, studied this phenomenon by leaving a Brinell-type dimple of a certain diameter and showed that the greatest arrest of crack growth due to the compressive stresses was caused by forming the dimple.

It is obvious that each repair procedure has advantages and disadvantages; this paper focuses on the requirement of hybrid repair method by combining a bonded patch with drilled stop hole, that enhances the residual strength of the damaged structures. The combination between two techniques can offer a possibility of complementarity and eliminate the weaknesses of the two techniques. Few studies on this combination exist in the literature in fact, there are several studies concerning hybrid joints, we can mention the work of [17-19].

In this work, three-dimensional finite element analyzes are performed to compare the effectiveness of the hybrid repair technique with composite patches and the drilling hole to repair an aluminum plate containing $\mathrm{U}$ lateral notches. A volumetric approach is developed to obtain the notch stress intensity factor $K_{\rho}$ in mode-I condition [20]. Variation of notch bottom opening stress fields in the different methods was examined based on the notch stress intensity factor (NSIF). The plastic zone at the U-Notch front has been studied as part of a drill hole, bonded repair and hybrid method repair. In addition, the variation in peel stresses in the plate / adhesive interface area for single patch repair and hybrid repair has also been checked.

\section{Volumetric method $\left(K_{\rho}\right)$}

The stress field around the notch-tip in mode I condition and subsequent evaluation of the notch stress intensity factor $\mathrm{K}_{\rho}$ are performed to describe the fracture criterion. The determination of the $\mathrm{K}_{\rho}$ is made using the volumetric approach [20], this method was chosen because it is feasible to give the appropriate $K_{\rho}$ values before and after the repairs.

It assumed that the fracture process needs a physical volume where the necessary fracture energy release rate is stored to launch the fracture phenomenon; it corresponds to the high stressed region in which the fracture notch effect is taking place. This leads to a volumetric approach; two parameters are describing this fracture criterion: the effective distance and the effective stress. A bi-logarithmic graph shown in Fig. 1, represent the stress distribution at the notch tip where the stress normal to the notch plane is plotted versus the distance, and the effective stress and distance are also shown. 

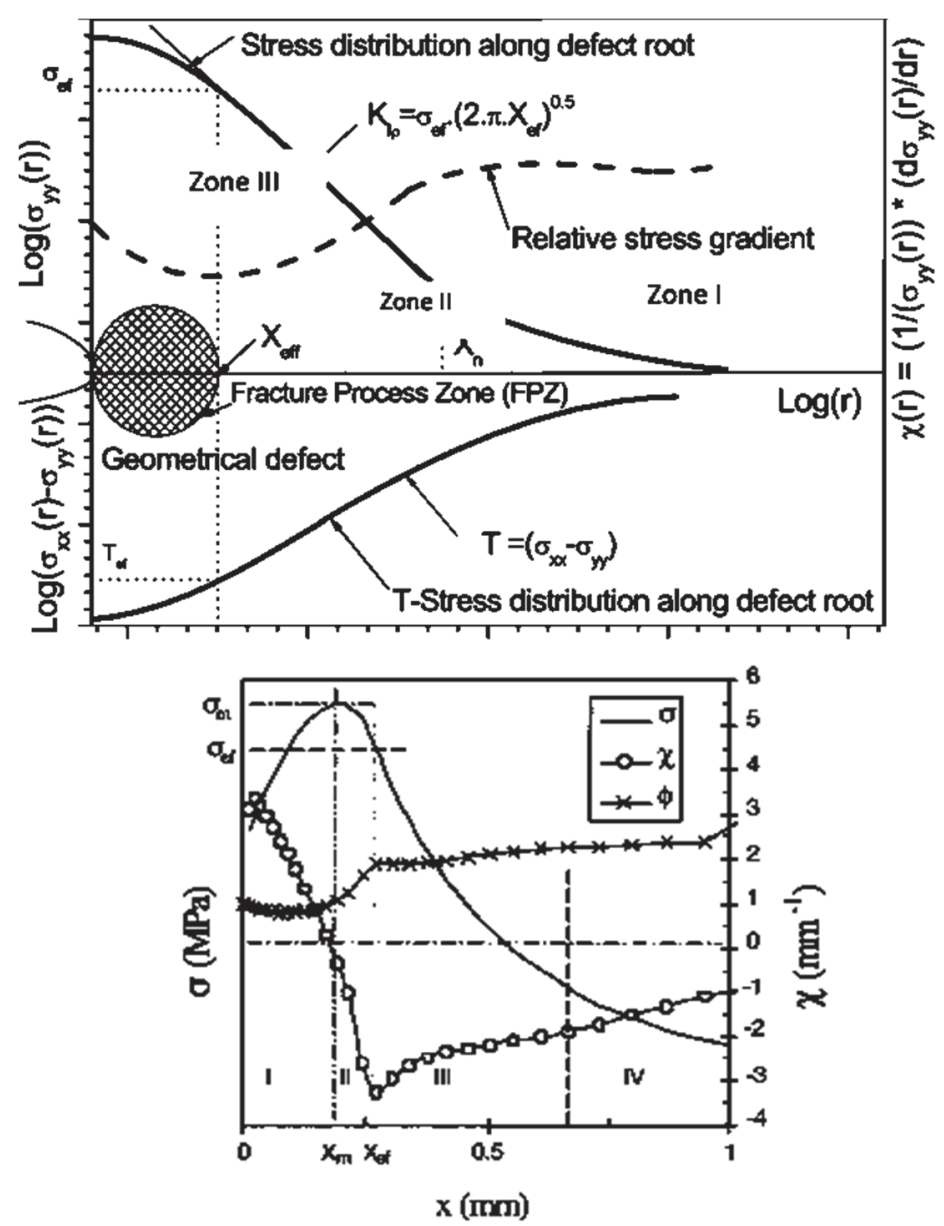

Figure 1: Stress distribution at the notch tip where the stress normal to the notch plane versus the distance from end notch [20]

From the above graph, it can be distinguished three zones, i) the high stressed zone (zone I) in which the stress distribution achieves a maximum value offset by a distance from the notch root, ii) in the (zone II) the stress value is decreasing to the outside of the notch root, iii) the evaluation of the stress (zone III) takes a linear behavior. The effective distance was determined from the value of the minimum of the relative stress gradient $\chi$ defined by:

$$
\chi=\frac{1}{\sigma_{y y}} \cdot \frac{d \sigma_{y y}}{d r}
$$

where $\chi$ is the relative stress gradient and $\sigma_{\mathrm{yy}}$ is the maximum principal stress or opening stress.

From the relative stress gradient plotted on logarithmic graph Fig. 2, the effective distance $\mathrm{X}_{\mathrm{ef}}$ was obtained with the minimum of $\chi$. While from the plot of stress distribution over the effective distance, the effective stress for fracture $\delta_{\text {ef }}$ was considered as the average value over the effective distance. The stress distribution is then given by:

$$
\sigma_{e f}=\frac{1}{X_{e f}} \int_{0}^{X_{e f}} \sigma_{y y} \cdot(1-r) \cdot \chi d r
$$

however, the notch stress intensity factor is a function of the effective distance and the effective stress:

$$
K_{\rho}=\sigma_{e f} \cdot\left(2 \pi X_{e f}\right)^{a}
$$

where $K_{p}$ is the notch stress intensity factor and $\sigma_{\text {ef }}$ and $X_{\text {ef }}$ are the effective stress and effective distance, respectively, and $\alpha$ is the slope of the stress distribution in region III. The exponent $\alpha$ depends on the notch angle and is equal to $\alpha$ $=0.5$ if the sides of the notch are parallel. 


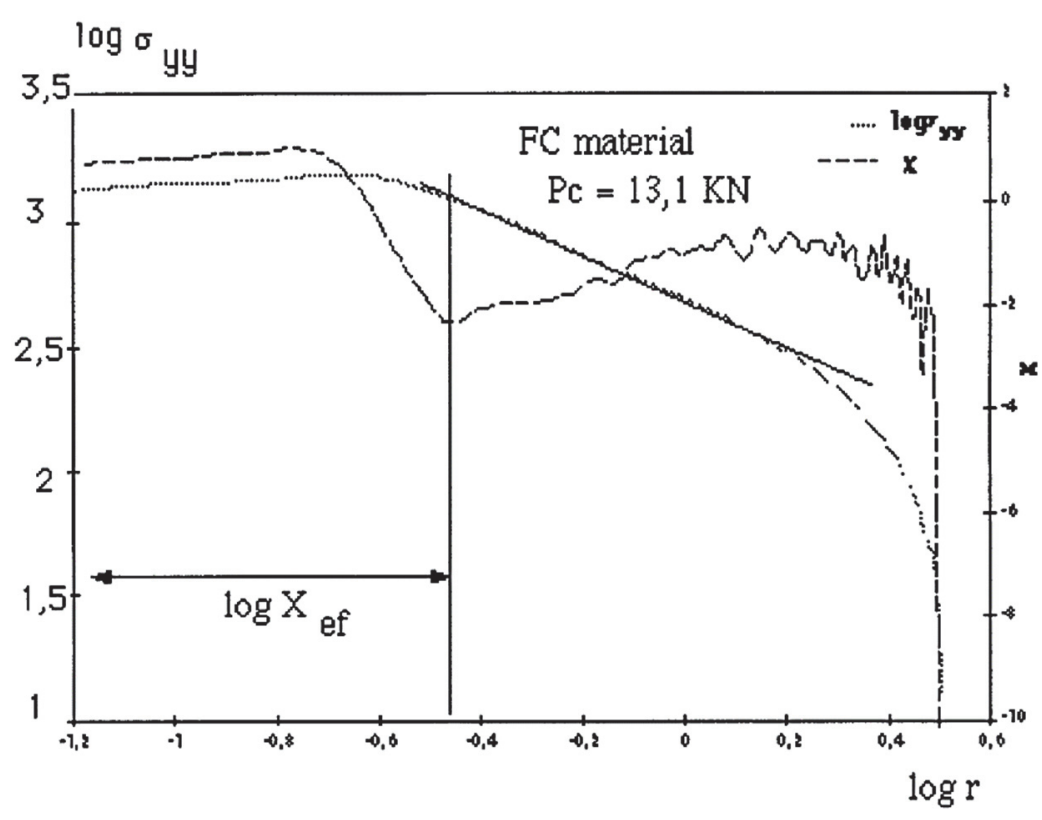

Figure 2: Stress distribution at the notch root together with relative stress gradient.[20]

\section{GEOMETRICAL AND MATERIAL PROPERTIES}

$\Lambda$ typical basic geometry and loading, adhesive layer and composite patch are shown in Fig. 3, the plates were made of a 2024-T3 Aluminum alloy containing lateral U- notch repaired with boron/epoxy composites and bonded with a thin layer of FM73 adhesive, subjected to a uniaxial loading of $65 \mathrm{MPa}$. The plate has the following dimensions: length $=160 \mathrm{~mm}$, width $=39 \mathrm{~mm}$, thickness $=3 \mathrm{~mm}$ and the dimensions of the notch are: radius $\varrho=0.25 \mathrm{~mm}$, length $=9.75 \mathrm{~mm}$ the length of one side square patch repair is $25 \mathrm{~mm}$ and its thickness is $1.5 \mathrm{~mm}$. the thickness of adhesive is $0.1 \mathrm{~mm}$. Material properties of the aluminum plate, adhesive and composite patch are given in Tabs. 1 and 2. The plate and the adhesive are considered as isotrop while the composite patch is modeled as an orthotrop [21,22].

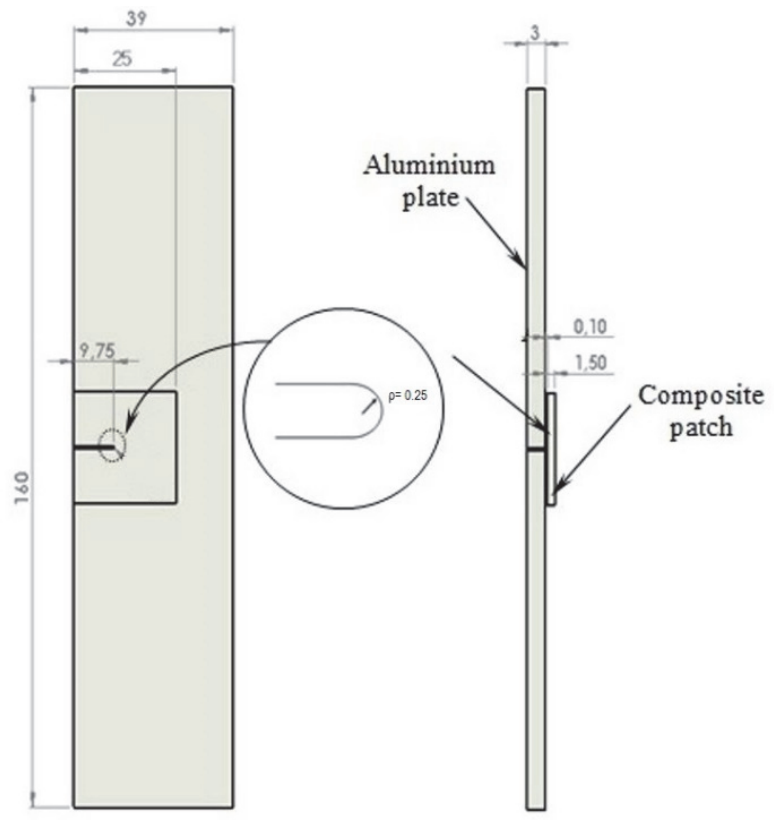

(a)

(b)

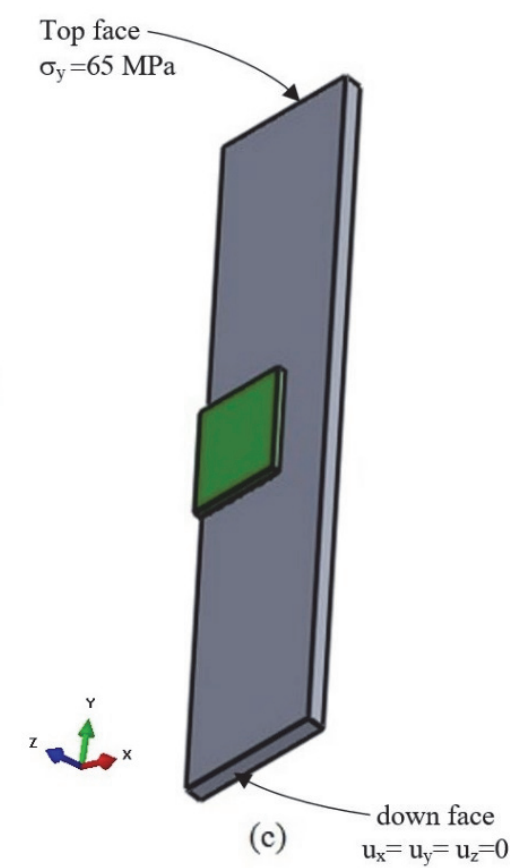

Figure 3: Geometry of the repaired model. (a) front view (b) side view (c) 3D view 


\begin{tabular}{|c|c|c|c|c|c|}
\hline Parameters & & \multicolumn{2}{|c|}{ Aluminum alloy 2024T3 } & \multicolumn{2}{|c|}{ Adhesive FM73 } \\
\hline $\mathrm{E}(\mathrm{GPa})$ & & \multicolumn{2}{|c|}{72} & \multicolumn{2}{|c|}{2.21} \\
\hline 0 & & \multicolumn{2}{|c|}{0.3} & \multicolumn{2}{|c|}{0.43} \\
\hline \multicolumn{6}{|c|}{ Table 1: Material properties of 2024-T3 aluminium alloy and FM 73 Adhesive } \\
\hline \multicolumn{2}{|c|}{$\begin{array}{l}\text { Elasticity modulus } \\
(\mathrm{GPa})\end{array}$} & \multicolumn{2}{|c|}{ Shear modulus $(\mathrm{GPa})$} & \multicolumn{2}{|c|}{ Poisson's ratio } \\
\hline $\mathrm{E}_{11}$ & 200 & $\mathrm{G}_{11}$ & 7.2 & $v_{12}$ & 0.21 \\
\hline $\mathrm{E}_{22}$ & 25 & $\mathrm{G}_{22}$ & 5.5 & $v_{13}$ & 0.21 \\
\hline $\mathrm{E}_{33}$ & 25 & $\mathrm{G}_{33}$ & 5.5 & $\mathrm{U}_{23}$ & 0.21 \\
\hline
\end{tabular}

Table 2: Material properties of composite patch boron/epoxy

\title{
FINITE ELEMENT MODEL
}

\begin{abstract}
finite element method (FEM) using ABAQUS software suite is employed for modeling the notched plates; a A typical finite element geometry, loading and mesh configuration of the notched plate are shown in Fig. 3.

1 The structure made up on the plate, the adhesive and the patch are subjected to uniform uniaxial tensile load of $65 \mathrm{MPa}$ on the section of the plate in $\mathrm{Y}$ direction, then clamped the down surface in the three directions. These conditions are represented in a 3D model as shown in Fig. 3

The mesh was modeled in 3D stress element type with 20-node quadratic brick geometric order and with a hexagonal element shape. A very fine mesh was generated for the region close to the notch-tip with an element dimension of $0.05 \mathrm{~mm}$ Fig. 4.

The tie between the plate-adhesive and patch-adhesive was created using "TIE" constraint, which allows the part instances to combine together.

In this analysis, the stress fields of the repaired plates are obtained to compare between the different repair techniques than to get the curve opening stresses versus the crack patch in order to extract the stress notch intensity factor $K_{p}$ determined analytically using the volumetric approach.
\end{abstract}

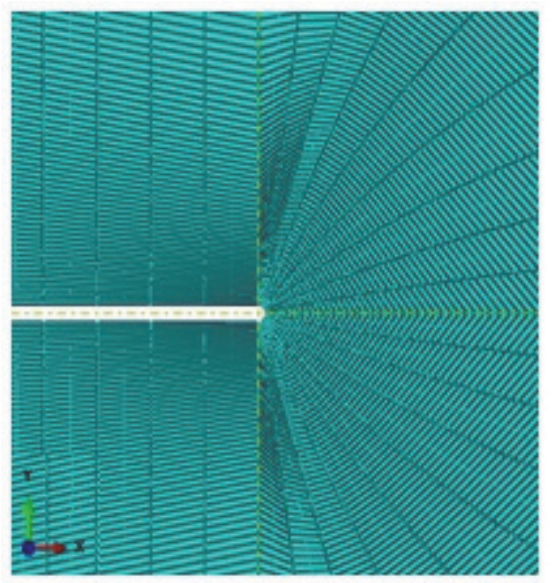

Figure 4: Finite element mesh of the notched plate.

\section{ANALYSIS AND RESULTS}

7 he evaluation of the effectiveness of the repair of cracked structures by the method of drilling a hole, push us to adopt the volumetric technique as a criterion because it allows us to use the notch stress intensity factor this factor is assimilated to the stress intensity factor for an elastic material. This factor is one of the parameters which providing a characteristic of the stress field existing near the crack tip. 
Validation of the choice of the drilling technique

The ruins of cracked structures depend on several parameters, namely the size of the crack its geometry or shape, the type of loadings and its amplitude. The repair of a cracked structure by the hole drilling method at the bottom of the crack is based on the geometric modification of the crack eliminating the singularity in its tip, this causes a relief of the structure solicited and offers the possibility to leave the structure in service the time to prepare for its replacement otherwise the repair can be permanent.

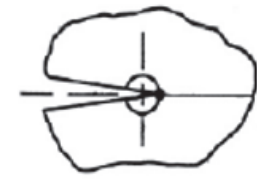

(A)

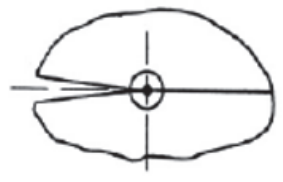

(B)

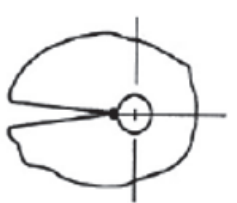

(C)

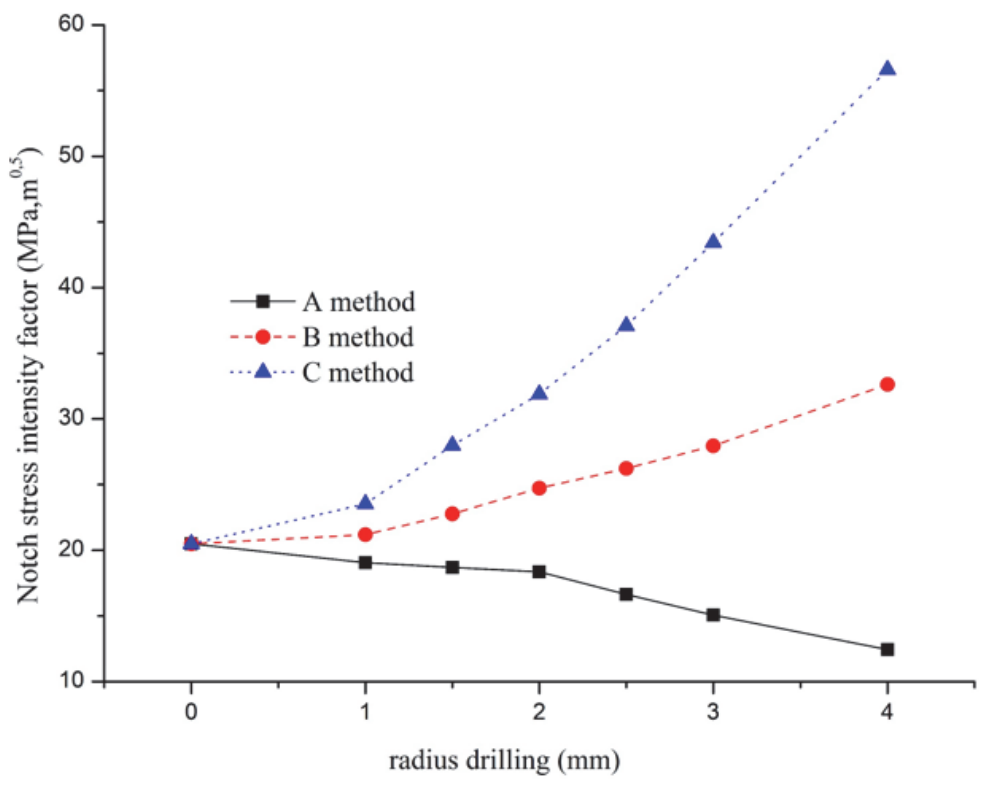

Figure 1: The notch stress intensity factor $K_{\rho}$ vs notch radius for three methods $A, B$ and $C$.

Researchers boost this interesting technique. The [23] and [24] investigated the possibility of drilling several holes near the bottom of the crack. Drilling a hole near the point of the crack increases the service life of the crack. structure and also influences the direction of propagation of the crack [6].

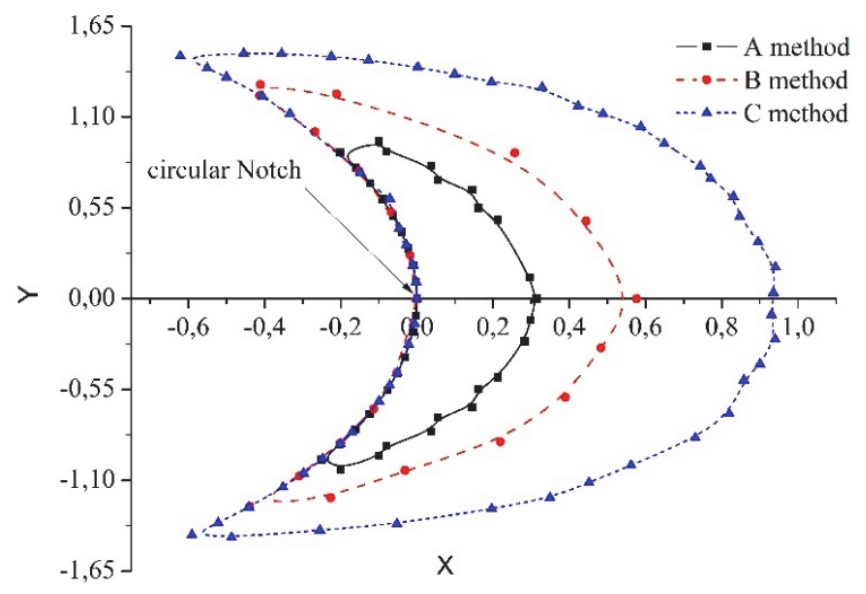

Figure 2: Plastic zone size vs drilled methods A, B and C.

In the perspective of validating our numerical model. The choice of piercing method is compared with the results of [25]. Fig. 5 presents the variation of the notch stress intensity factor as a function of the drilling radius for the three 
drilling methods proposed by [25], our results valid and confirm the conclusion of [25], indeed the notch stress intensity factor decreases only in method " A " as a function of drilling radius.

In addition, the evaluation of the beneficial effect of the repair by drilling hole depending on the notch stress intensity factor Ke can be assessed by analyzing the distribution of axial stresses $\sigma_{22}$ and the size of the plastic zone in the vicinity of the drilling hole. Fig. 6. Show the size of plastic zone (SPZ) for three drilled methods. As it, we can observe the development of plastic zones, because the presence of the weak concentrations of deformations in the bottom of the crack engendered by the removal of the material for the three methods of drilling, still with the size of plastic zone the technique of piercing (A) proves its interest.

\section{Hybrid repair Technic}

In recent years, several researchers have invested in assembling structures with joint or hybrid joints (weld + rivet, clinch + bonded [18], bonded + riveted [26], bonded + bolted [17]) to improve the individual performance of each type of joint. Hybrid joint applications are of major interest in aerospace technology and engineering. Experimental studies have demonstrated that certain assemblies can achieve high static strength over riveted, bonded, or bolted assemblies separately [27-29]. Compared to a riveted structure only, the hybrid assembly reduces the number of rivets and improves the strength of the structure.

However, the repair of cracked structures is one of the areas where hybrid assemblies or hybrid repair can be used, our study is aimed at this empty domain. We will investigate numerically in the hybrid repair (collage - drilling) based on the notch intensity factor, the distribution of the $\sigma_{\mathrm{yy}}$ stress, the size of the plastic zone at the bottom of the notch, crack type opening displacement (CTOD), finally the peel stress.

\section{Distribution of $\sigma_{y y}$ stress}

Fig. 7 shows the distribution of the normal stress $\sigma_{y y}$, in fig. 7 (a) and the fig. 7 (b) illustrates max $\sigma_{y y}$ distribution through plate thickness

The stress concentration at the bottom of the notch shows two stress levels in fig. 7(a), a maximum between 370 and $470 \mathrm{MPa}$ and a second level between 148 and $250 \mathrm{MPa}$, we can also see that far from the notch bottom in the relaxation zone of plate, two other levels of stress appear, the non-repair plate is relaxing at a stress level of $120 \mathrm{MPa}$, the drilled plate has a lower level of $90 \mathrm{MPa}$, while the level of the constraints of the two repair techniques is practically superimposed view that in both techniques the composite absorbs virtually all the stresses generated by mechanical solicitation.

Plotting the max $\sigma_{\mathrm{yy}}$ in fig. 7 (b) and comparing these results it is found that the drilling plate provides a reduction of $21 \%$ of the max $\sigma_{y y}$, the second level offered by the two repair techniques, these techniques carries out reduced rates of $46 \%$ for single-composite repair and 68\% for hybrid repair (single-patch drilling).
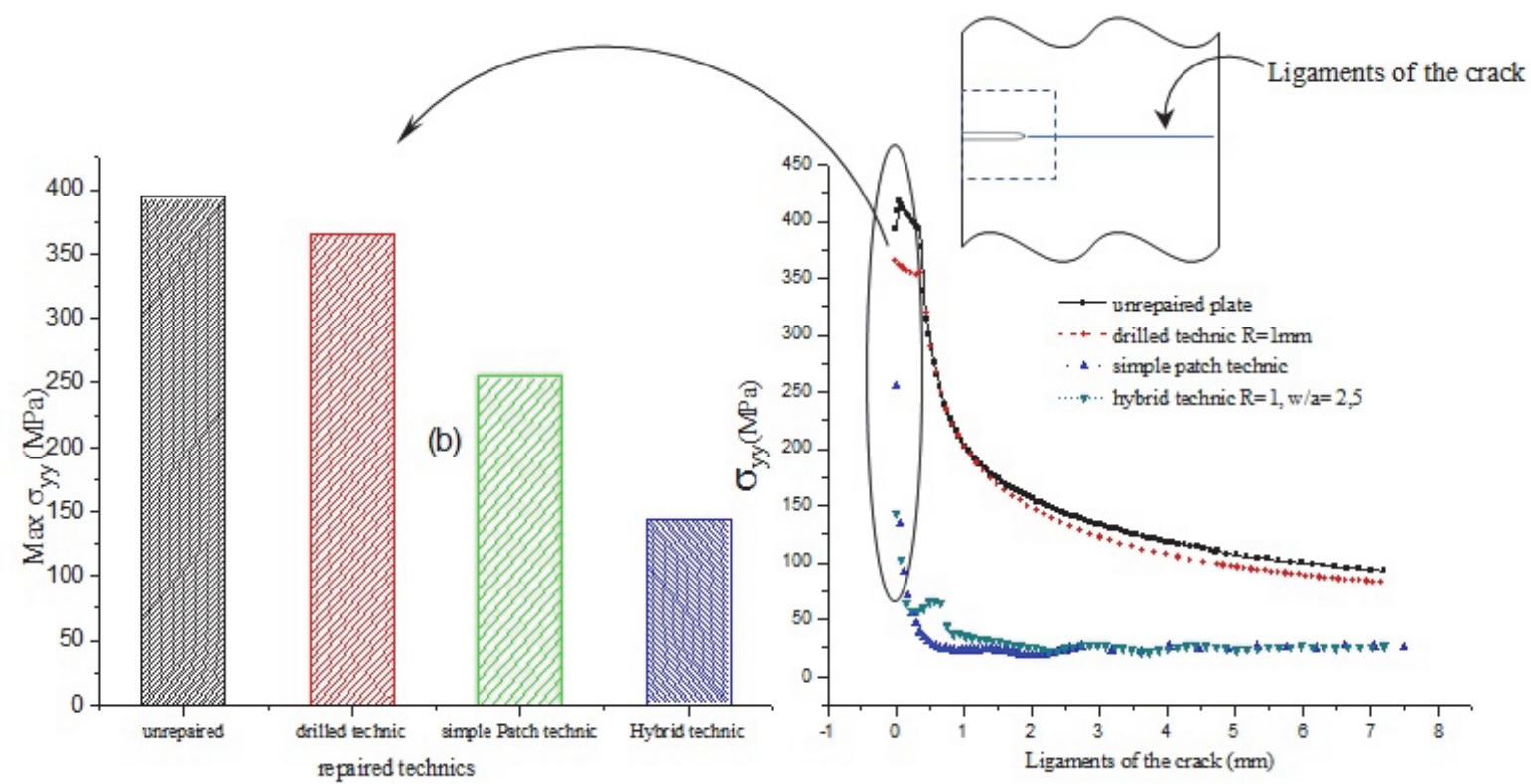

Figure 3: Distribution of $\sigma_{\mathrm{yy}}$ stress along the ligaments of the crack (a), and variation of the max $\sigma_{\mathrm{yy}}$ for different cases (b)

The distribution of the normal stress $\sigma_{\mathrm{yy}}$ along the plate thickness is plotted against all studied cases in fig. 8 (a), averaged $\sigma_{y y}$ for same cases repairs technics in fig. 8(b). 

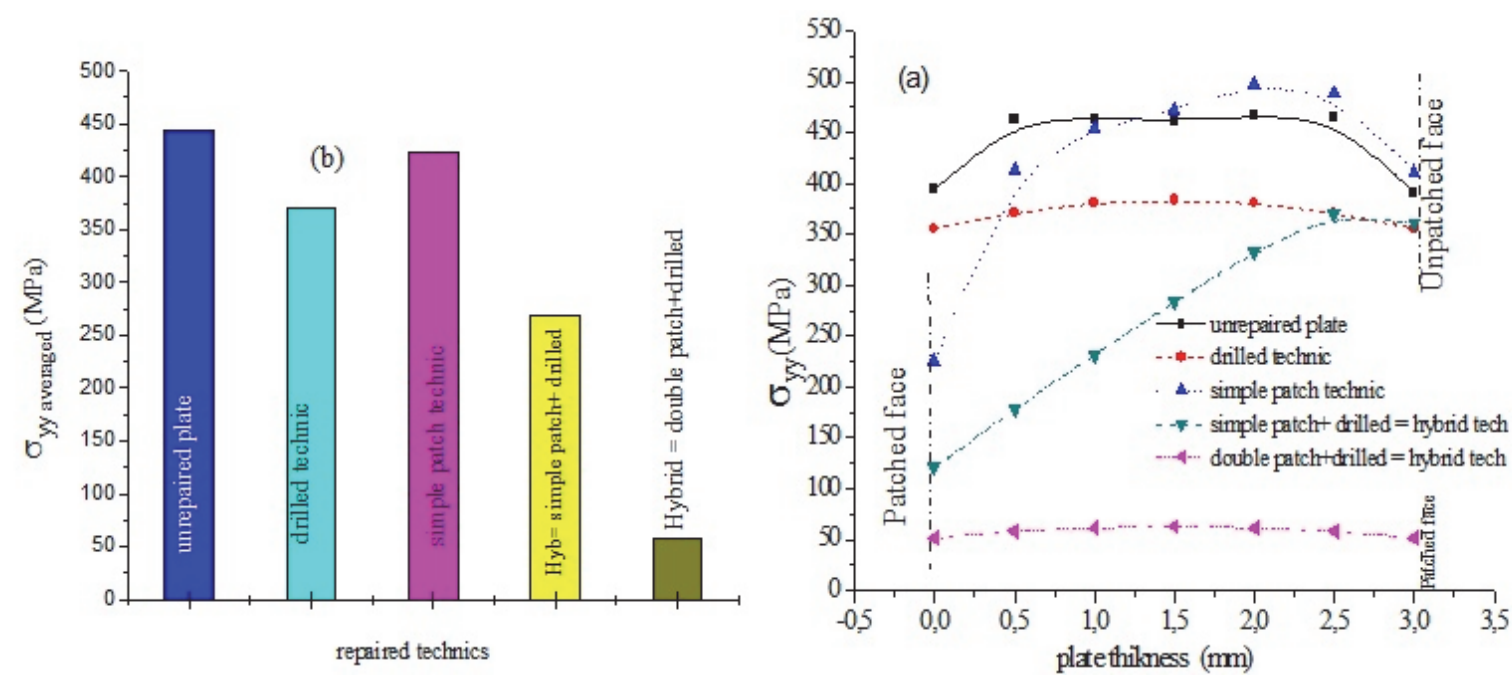

Figure 4: Normal stress $\sigma_{\mathrm{yy}}$ distribution along the plate thickness for all cases.

A comparison of the normal stress level for the types of repair considered allows us to conclude that the majority of the resistance of the hybrid repair with a simple patch comes from the adhesive and proposed as the best compared to the others with $44 \%$ of reduction compared to the structure repaired by simple patch only. However, the addition of a second patch on the other side of the plate (double patch) increases greatly the energy absorption capacity of the hybrid repair. In the case considered, this increase was equal to $80 \%$.

\section{Notch stress intensity factor}

After analyzing the maximum normal stress $\sigma_{y y}$, we also analysed the notch stress intensity factor (NSIF), which is another parameter of failure. The result above shows a strong decrease in stress concentration in the vicinity of the notch bottom caused by the application of the bonded composite.

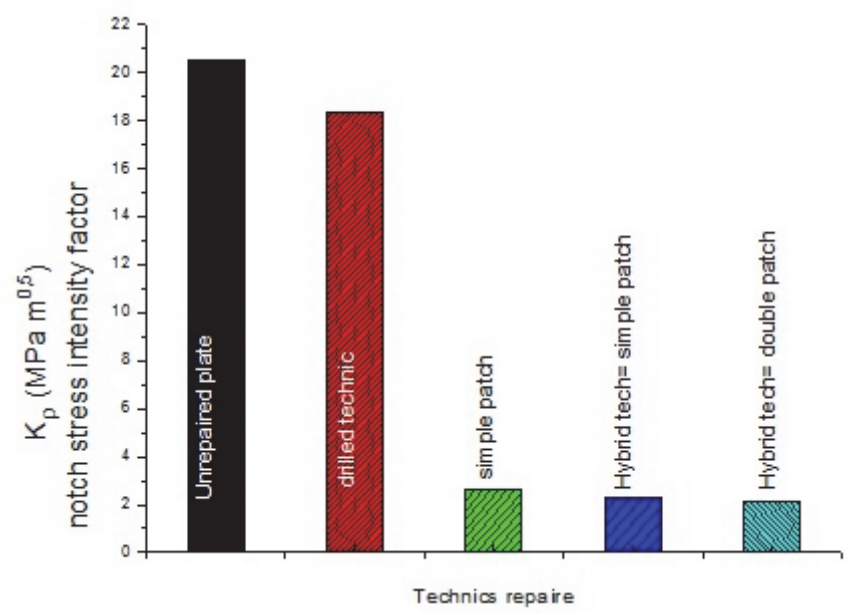

Figure 5: The notch stress intensity factor $K_{\rho}$ vs repair technics system.

Fig. 9 demonstrates the comparability of the notch stress intensity factor (NSIF) $K_{\rho}$ for the repair technics system, one can note that the drilling of the plate offers a reduction of the NSIF of $10 \%$ compared to the unrepaired plate, for the repair system by patch only the rate of reduction is $83 \%$, while the hybrid repair (simple patch + drilling) offers a drop of the NSIF of the order $88 \%$ of the same hybrid repair (double patch + drilling) led to a further reduction of $90 \%$. Indeed, the singularity at the bottom of the notch removed by the piercing provides additional relaxation to the damaged structure.

The central parts of the adhesive in the vicinity of the pierced zone are subjected to a low level of stress and do not support a high load, since the patch absorbs the majority of the stresses caused by the uniaxial solicitation.

\section{COD parameter}

Ductile materials can break at relatively low stress levels since the deformation is limited to the vicinity of the relatively large crack tip. To characterize the fracture behaviour of these materials, we have used parameters similar to critical 
crack opening displacement (COD), critical-crack-tip opening displacement (CTOD) or crack stretching ( 8 ). The criticalcrack-tip opening displacement CTOD can be converted into stress intensity after which it can be used directly to predict the breaking of large structures. The CTOD value is extracted from a fixed node in face of the initial crack tip [30].

The COD value is extracted from a fixed node in the end line of the initial crack tip (Fig. 10). The variation COD parameters for five cases studies is presented in Fig. 11, It can be observed from Fig. 11 that, for both simple patches only technic and hybrid technic (simple patch + drilled) the COD are comparatively similar, this is because most of the strength of the hybrid joint comes from the adhesive. However, the application of a second composite patch on the other side of the plate increases greatly the energy absorption capacity of the hybrid repair system (double patch + drilled).

\section{Plastic zone}

It was pointed out that the analysis of the extent of the plastic zone has shown that the plastic zone has completely disappeared by applying the hybrid repair technic, for this reason it is wished to make a comparison with respect to the unrepaired face of the plate by a simple patch only and hybrid repair (simple patch + drilling).

The results of Fig. 11 show that the hybrid repair leads to the decrease of the COD parameter and consequent to the decrease in the size of the plasticized zone at the crack tip (Fig. 12). This illustrates the extent of the plastic zone for different repair techniques. The extents of the plasticized areas were determined using the Von Mises criterion.

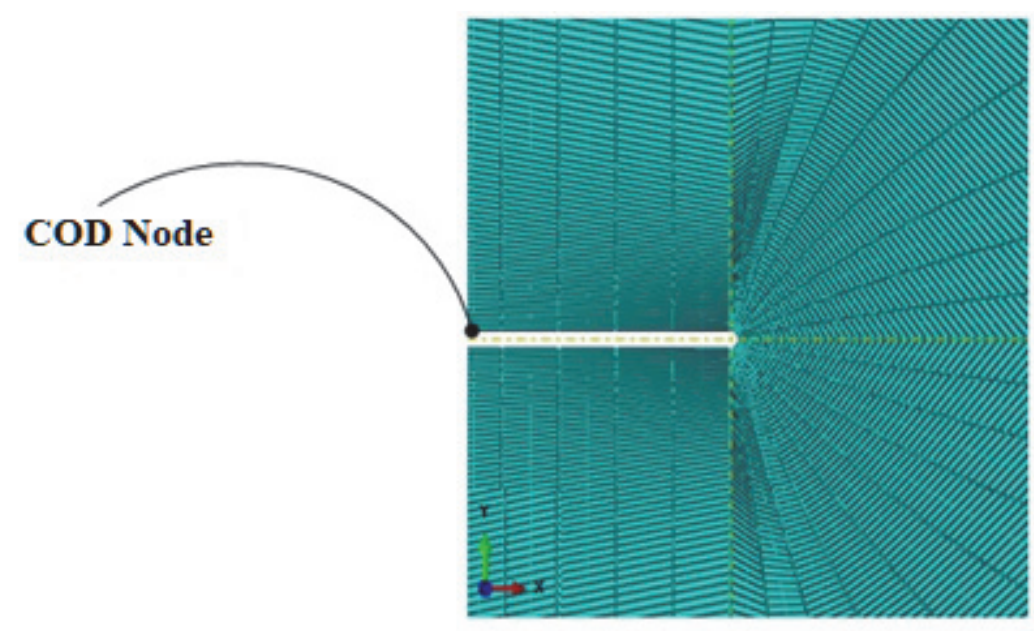

Figure 6: Schematic plot of the COD-node.

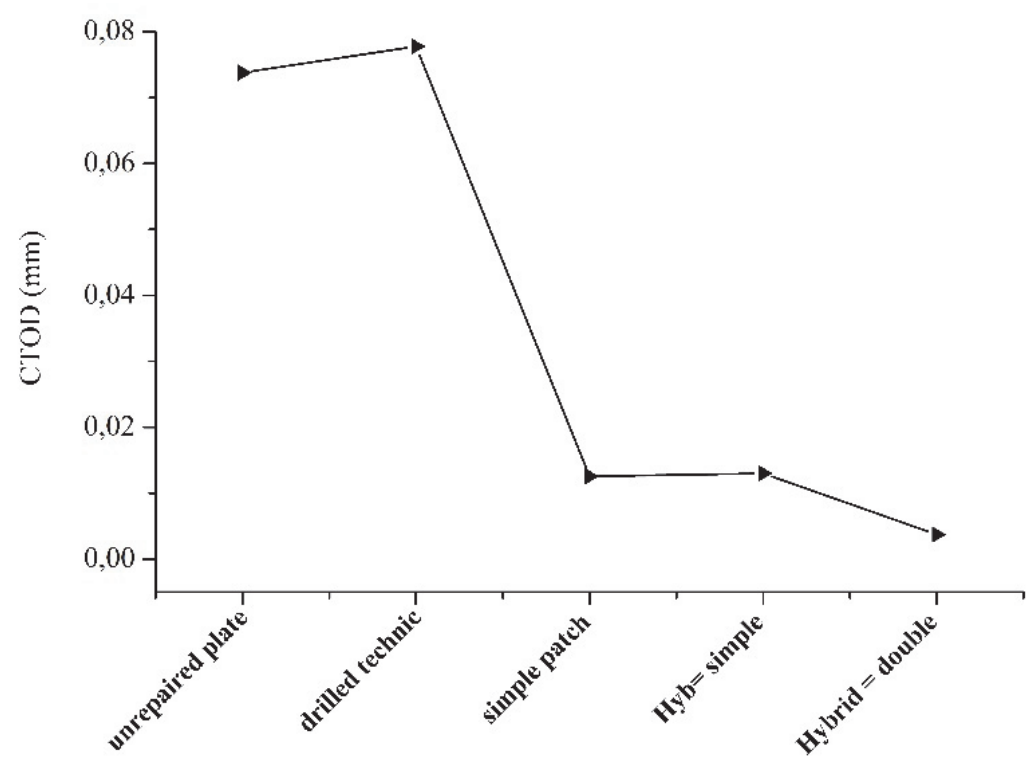

Figure 7: Variation of COD parameters for the five studied cases. 


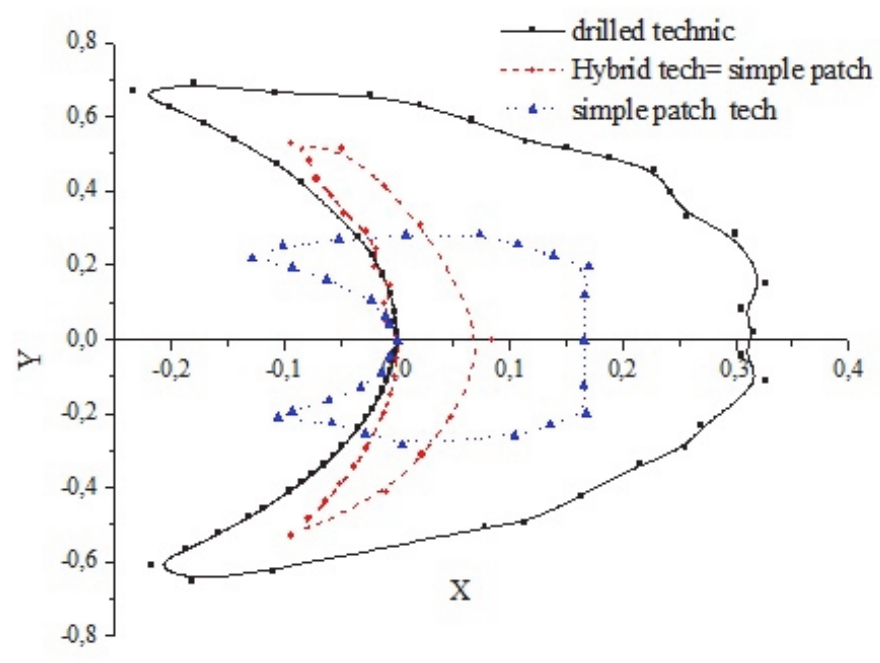

Figure 8: Variation of plastic zone size for the three studied cases.

At the crack tip the deformation fields are considerable and result in a larger area of the plastic zone [22]. In this case, the mechanical energy at the crack head is absorbed by the material in the form of defects. The higher this energy is, the higher of the defect density increases leading to a large size of the plastic zone. The sizes of the plasticized zones obtained for the hybrid technique are small compared to those obtained for the drilled hole repair and single patch only. Indeed, the area of the plastic zone for the drilling hole technique is worth almost six times that of the hybrid technique, this confirms the effectiveness of the hybrid repair system.

Peel stress $\left(\sigma_{\text {zi }}\right)$

As we know, disband is one of the major weaknesses of bonded composite repair, these initiating causes are generally the bad preparation of bonding surfaces, the low resistance of the adhesive in shear load or peel stress, high concentration of stress at the crack tip, etc.

On the other hand, the adhesive is the weak link of reinforcement by composite materials. It is a material with very low mechanical shear properties and it is known that takeoff is started with the development of peel stress concentrations $\left(\sigma_{z z}\right)$ [32], [33].

In our study, we focus on the peel stress. Fig. 13 shows the distribution of the peel stress $\left(\sigma_{z z}\right)$ along the virtual line for tow type of repair systems (simple patch + drilling). We find that the distribution of stress peel is similar except at the tip of the notch for the hybrid repair with a reduction of $80 \%$, it is clear that the use of a hybrid repair generates low peel stresses near the notch front and therefore decreases the probabilities of disband phenomena. The use of hybrid repair technic is recommended to extend the life of cracked structural components and give a better performance and eliminating the disadvantages of each type of repaired system (bonded composite and drilled hole).
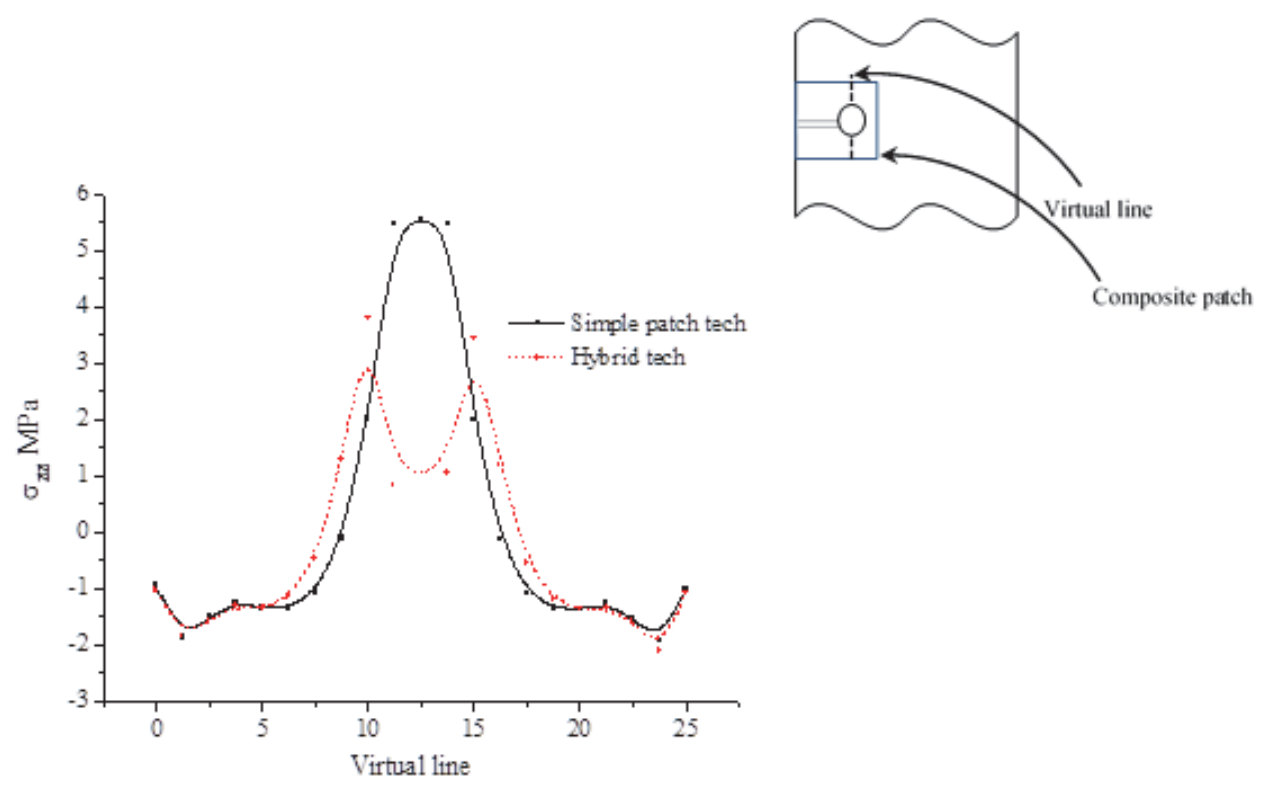

Figure 9: Peel stress $\left(\sigma_{\mathrm{zz}}\right)$ distribution along the virtual line. 


\section{Verification with other models}

Fig.15 are plotted to see more clearly about the behaviour of different configurations of repair system, where the maximum values of the normal stress $\left(\sigma_{\mathrm{yy}}\right)$ are assembled in histograms forms.

Rodriguez-Sanchez et al [31] proposed five drill crack repair configurations (Fig. 14): (a) Through hole, (b) Bottom hole, (c) hole with notch to symmetric inclined faces, (d) hole with notch with asymmetrical inclined faces, (e) hole and inclined notch.

In this analysis, we applied hybrid repair to these configurations for specific cases. Fig. 15 shows a comparison between the repair proposed by Rodriguez [31] and the application of the composite bonded on these same configurations for the cases chosen, this figure leads us to conclude that the hybrid configuration is the best whatever the model chosen, because it always reduces the stress concentrations in a significant way at the bottom of the notch.

In the (e) model the maximum $\sigma_{y y}$ value is significantly the bottom-most lower than the other models without bonded patch, so with the composite patch it decreases by seven times compared to the drilled hole case only.

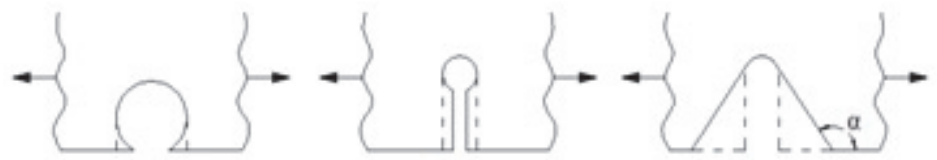

(a) (c)

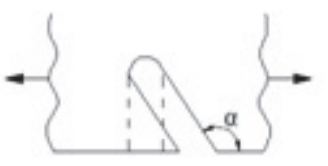

(e)

Figure 10: Equivalent notch configurations [31]

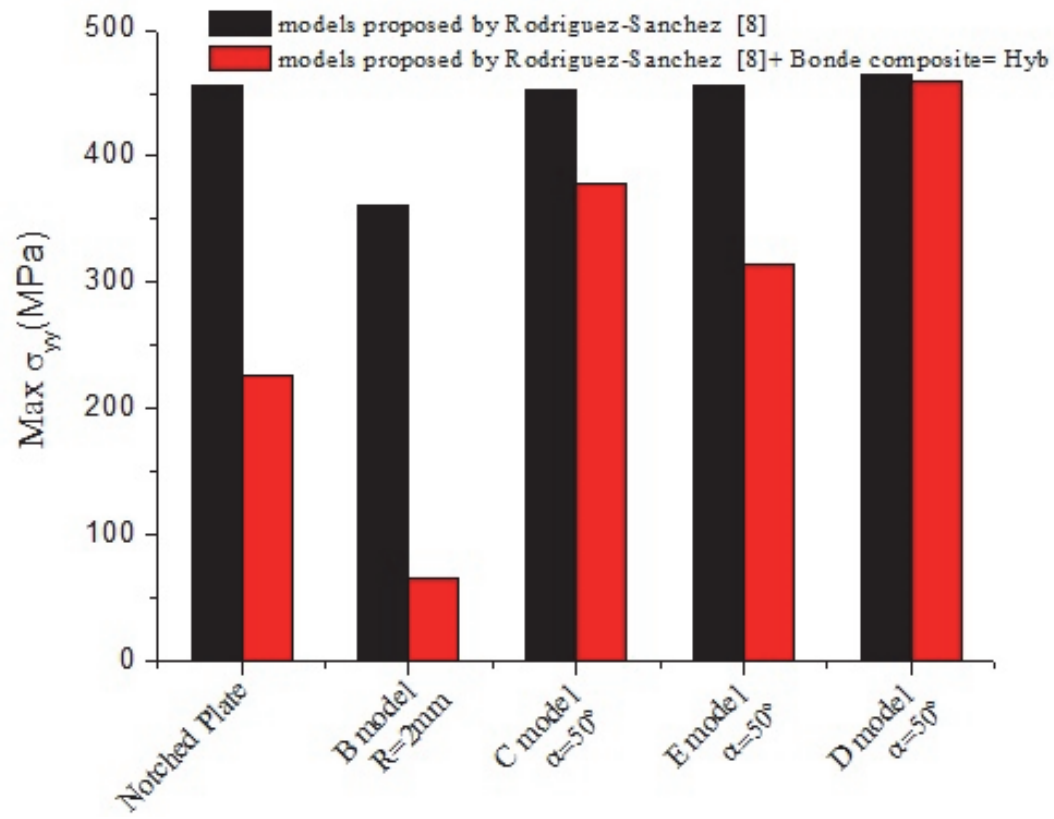

Figure 11: Maximum $\sigma_{\mathrm{yy}}$ value for each type of repair systems.

\section{CONCLUSION}

$\mathrm{I}$ $\mathrm{n}$ this work crack repair by hole drilling, composite bonding and the combination of both (hybrid) have been studied numerically. The results obtained from finite element analysis in this paper lead us to the following conclusions:

Hybrid repairs (single and double patch + drilled hole) provide better static performance than other configurations. 
The singularity at the bottom of the notch removed by the piercing provides additional relaxation to the damaged structure.

The hybrid repair leads to the decrease of the COD parameter and consequently to decrease the size of the plasticized zone at the bottom of the crack.

Finite element analyzes have shown that the presence of the two-side bonded composite can reduce significantly the maximum peel stress at the interface (plate/adhesive), which helps attain better repair performance.

\section{REFERENCES}

[1] Baker, A. A., Rose, L. R. F. and Jones, R. (eds) (2002) Advances in the bonded composite repair of metallic aircraft structure. 1st ed. Amsterdam; Boston: Elsevier.

[2] Song, P. S., Hwang, S. and Shin, C. S. (1998). Effect of artificial closure materials on crack growth retardation, Engineering Fracture Mechanics, 60(1), pp. 47-58. DOI: 10.1016/S0013-7944(97)00180-X.

[3] Fu, Z., Ji, B., Xie, S. and Liu, T. (2017). Crack stop holes in steel bridge decks: Drilling method and effects, Journal of Central South University, 24(10), pp. 2372-2381. DOI: 10.1007/s11771-017-3649-8.

[4] Murdani, A., Makabe, C., Saimoto, A., Irei, Y. and Miyazaki, T. (2008). Stress concentration at stop-drilled holes and additional holes, Engineering Failure Analysis, 15(7), pp. 810-819. DOI: 10.1016/j.engfailanal.2007.11.002.

[5] Ghfiri, R., Shi, H.-J., Guo, R. and Mesmacque, G. (2000). Effects of expanded and non-expanded hole on the delay of arresting crack propagation for aluminum alloys, Materials Science and Engineering: A, 286(2), pp. 244-249. DOI: 10.1016/S0921-5093(00)00805-4.

[6] Goto, M., Miyagawa, H. and Nisitani, H. (2007). Crack growth arresting property of a hole and Brinell-type dimple, Fatigue \& Fracture of Engineering Materials \& Structures, 19(1), pp. 39-49.

DOI: $10.1111 /$ j.1460-2695.1996.tb00930.x.

[7] Kirkhope, K. J., Bell, R., Caron, L., Basu, R. I. and Ma, K.-T. (1999). Weld detail fatigue life improvement techniques. Part 1: review, Marine Structures, 12(6), pp. 447-474. DOI: 10.1016/S0951-8339(99)00013-1.

[8] Rodriguez-Sanchez, J. (2004). Application of short repairs for fatigue life extension, International Journal of Fatigue, 26(4), pp. 413-420. DOI: 10.1016/j.ijfatigue.2003.07.002.

[9] Wu, H., Benseddiq, N. and Imad, A. (2010). Fracture toughness prediction of a valve body: Numerical analysis, Engineering Failure Analysis, 17(1), pp. 135-142. DOI: 10.1016/j.engfailanal.2009.04.010.

[10] Elber, W. (1971). The Significance of Fatigue Crack Closure, in Rosenfeld, M. (ed.) Damage Tolerance in Aircraft Structures. 100 Barr Harbor Drive, PO Box C700, West Conshohocken, PA 19428-2959: ASTM International, DOI: $10.1520 /$ STP26680S.

[11] Newman, J. (1976). A Finite-Element Analysis of Fatigue Crack Closure', in Rice, J. and Paris, P. (eds) Mechanics of Crack Growth. 100 Barr Harbor Drive, PO Box C700, West Conshohocken, PA 19428-2959: ASTM International. DOI: 10.1520/STP33952S.

[12] Newman, J. and Elber, W. (eds) (1988) Mechanics of Fatigue Crack Closure. 100 Barr Harbor Drive, PO Box C700, West Conshohocken, PA 19428-2959: ASTM International. DOI: 10.1520/STP982-EB.

[13] Robin, C., Louah, M. and Pluvinage, G. (1983). Influence of an overload on the fatigue crack growth in steels, Fatigue \& Fracture of Engineering Materials and Structures, 6(1), pp. 1-13. DOI: $10.1111 /$ j.1460-2695.1983.tb01135.x.

[14] Smith, D. J., Bourke, M. A. M., Hodgson, A. P., Webster, G. A. and Webster, P. J. (1992). Interpretation of residual stress distributions in previously loaded cracked beams, The Journal of Strain Analysis for Engineering Design, 27(2), pp. 77-83. DOI: 10.1243/03093247V272077.

[15] van Leeuwen, H. P., Meulman, A. E. and Schra, L. (1970) The Repair of Fatigue Cracks in Low-alloy Steel Sheet.

[16] Eggwerts, S., Garfall, L. and Wallgren, G. (1969). Review of some Swedish investigations on fatigue during the period April 1967 to March 1969.

[17] Fu, M. and Mallick, P. K. (2001). Fatigue of hybrid (adhesive/bolted) joints in SRIM composites, International Journal of Adhesion and Adhesives, 21(2), pp. 145-159. DOI: 10.1016/S0143-7496(00)00047-6.

[18] Moroni, F., Pirondi, A. and Kleiner, F. (2010). Experimental analysis and comparison of the strength of simple and hybrid structural joints', International Journal of Adhesion and Adhesives, 30(5), pp. 367-379.

DOI: 10.1016/j.ijadhadh.2010.01.005.

[19] Venkateswarlu, S. V. (2013). Modelling and Analysis of Hybrid Composite Joint Using Fem in Ansys, IOSR Journal of Mechanical and Civil Engineering, 6(6), pp. 1-6. DOI: 10.9790/1684-0660106.

[20] Pluvinage, G. and Gjonaj, M. (2001) Notch Effects in Fatigue and Fracture. DOI:10.1007/978-94-010-0880-8.

[21] Hosseini-Toudeshky, H., Saber, M. and Mohammadi, B. (2008). Mixed-mode 3-D crack propagation of repaired thin aluminum panels using single-side composite patches, International Journal of Fracture, 153(2), pp. 105-116. DOI: $10.1007 / \mathrm{s} 10704-008-9303-6$. 
[22] Oudad, W., Belhadri, D. E., Fekirini, H. and Khodja, M. (2017). Analysis of the plastic zone under mixed mode fracture in bonded composite repair of aircraft structures, Aerospace Science and Technology, 69, pp. 404-411. DOI: $10.1016 /$ j.ast.2017.07.001.

[23] Thomas, S. B., Mhaiskar, M. J. and Sethuraman, R. (2000). Stress intensity factors for circular hole and inclusion using finite element alternating method, Theoretical and Applied Fracture Mechanics, 33(2), pp. $73-81$. DOI: $10.1016 /$ S0167-8442(00)00002-1.

[24] Shin, C. (1996). Fatigue damage repair: a comparison of some possible methods, International Journal of Fatigue, 18(8), pp. 535-546. DOI: 10.1016/S0142-1123(96)00029-1.

[25] Khoshravan, M. R. and Hamidi, A. (2007). Numerical Analysis of the Influence of Location of the Stopping Holes in the Crack Growth, Journal of Aerospace Science and Technologie, 4(1), pp. 9-16.

[26] Gómez, S., Oñoro, J. and Pecharromán, J. (2007). A simple mechanical model of a structural hybrid adhesive/riveted single lap joint, International Journal of Adhesion and Adhesives, 27(4), pp. $263-267$. DOI: $10.1016 /$ j.ijadhadh.2006.01.004.

[27] Kweon, J.-H., Jung, J.-W., Kim, T.-H., Choi, J.-H. and Kim, D.-H. (2006). Failure of carbon composite-toaluminum joints with combined mechanical fastening and adhesive bonding, Composite Structures, 75(1-4), pp. 192-198. DOI: 10.1016/j.compstruct.2006.04.013.

[28] Chan, W. S. and Vedhagiri, S. (2001). Analysis of Composite Bonded/Bolted Joints Used in Repairing, Journal of Composite Materials, 35(12), pp. 1045-1061. doi: 10.1177/002199801772662325.

[29] Hart-Smith, L. J. (1985). Bonded-bolted composite joints, Journal of Aircraft, 22(11), pp. 993-1000. DOI: $10.2514 / 3.45237$.

[30] Kanninen, M. F., Broek, D., Marschall, C. W., Rybicki, E. F., Sampath, S. G., Simonen, F. A. and Wilkowski, G. M. (1976). Mechanical fracture predictions for sensitized stainless steel piping with circumferential cracks. [BWR].

[31] Rodriguez, J. E., Brennan, F. P. and Dover, W. D. (1998). Minimization of stress concentration factors in fatigue crack repairs, International Journal of Fatigue, 20(10), pp. 719-725. DOI: 10.1016/S0142-1123(98)00039-5.

[32] Ramji, M., Srilakshmi, R. (2012). Design of composite patch reinforcement applied to mixed-mode cracked panel using finite element analysis, J. Reinf. Plast. Compos., 71(2), pp. 258-70, DOI: 10.1177/0731684412440601.

[33] Oudad, W., Belhadri, D.E., Fekirini, H. and Khodja, M. (2017). Analysis of the plastic zone under mixed mode fracture in bonded composite repair of aircraft structures, 69, pp. 404-411, DOI: 10.1016/j.ast.2017.07.001. 